\title{
COMORBIDITY OF BODY DYSMORPHIC DISORDER AND PERSONALITY DISORDERS AMONG COSMETIC SURGERY VOLUNTEERS
}

\author{
Pegah Farokhzad ${ }^{1 *}$ and Marmareh Sehati ${ }^{2}$ \\ ${ }^{1}$ Dr., Dept. of Psychology, Islamic Azad University, Roudehen, IRAN, \\ dr.pegahfarokhzad@gmail.com \\ ${ }^{2}$ Ms., Islamic Azad University, Roudehen, IRAN, marmareh.sehatty@gmail.com \\ ${ }^{*}$ Corresponding Author
}

\begin{abstract}
This research was aimed to study the comorbidity of body dysmorphic disorder and personality disorders among cosmetic surgery volunteers and it was a correlational study. The statistical population of study consisted of 50 patients ( 25 males and 25 females) who were volunteers for cosmetic surgery and referred to "Key of Beauty Clinic" and were evaluated by Yale Brown Body Dysmorphic Scale and Milon Multidimensional Personality Questionnaire (Form 3). Data were analyzed using Pearson correlation method. Results showed that the mean of body dysmorphic disorder was higher in females comparing to males. Also, the correlation coefficients between body dysmorphic with subscales of avoidance, depression, hysteric, narcissistic, obsessive and self-harm in clinical patterns scale; body dysmorphic with subscales of schizotypal and severe personality patterns; body dysmorphic with subscales of anxiety, somatoform, manic, dysthymic in clinical symptoms scale; body dysmorphic with subscales of major depression in severe clinical symptoms scale were significant and 0.01 and 0.05 levels. On the basis of results of this research, it can be concluded that the applicants of cosmetic surgery were prominently vulnerable to components of mental disorders.
\end{abstract}

Keywords: Body Dysmorphic Disorder, Personality Disorder, Cosmetic Surgery.

\section{INTRODUCTION}

Every year, ten thousands of people undergo cosmetic surgery in order to change their physical appearance (Breuning, Oikonomou \& Singh, 2010). As reported by USA Plastic Surgery Association, 8.3 millions of cosmetic surgeries have been done in 2003 which is being increased 29 percent comparing to 1997 (Sarwer, Cash \& Magee, 1998). Also, on the basis of estimation of this association, the cosmetic surgery done in 2008 in being 12.1 million (Sarwer, Cash \& Magee, 2005). In our country, Iran, also in two previous decades the application for cosmetic surgery has been increased (Azizi et al., 2008 a); but the statistics related to 
cosmetic surgery in Iran is not clear as it is not recorded anywhere and the only information of this issue is estimated this way, as in some informal statistics the most cosmetic surgeries is being done in Iran and Brazil (Hamseda, 2010).

A high percent of youth application for cosmetic surgery in from females; as 95 percent of applicants are girls and females of 14 to 45 year for nose and skin surgery and 5 percent are males for nose surgery (Azizi et al., $2008 \mathrm{~b}$ ). The most of thought preoccupation is related to skin, hair, nose, eyes, eyebrows, lips, jaw and chin, however, it may not involve just one part and thought preoccupation would be on more parts simultaneously (Phillips, 2009). Research show that some of the effective factors on gravitation to cosmetic surgery are in-satisfaction of appearance, gaining ideal and dream appearance, gender, love partner, high socio-economic status (Pasha, Naderi \& Akbari, 2008; Grossbart \& Sarwer, 2003) and high educational level (Awami, 2009).

Body dysphormic disorder (BDD) is a relatively common and unknown disorder for both normal people and mental health professions; and people who have this disorder are the ones who go under surgery rather than treatment. According to high prevalence of this disorder and its daily increasing, few studies have been done in etiology and treatment of the disorder.

In 70 percent of cases, BDD begins before 18 year and its prevalence is reported to be 7 percent in general population (Otto et al., 2001), which is more prevalent in adolescents and young adults (Sarwer et al., 1998). Surveys of patients with BDD in psychiatric clinic have also shown the equal prevalence in both gender groups. There are similar features in pathology of BDD with obsessive-compulsive disorder (OCD) and social phobia and they have numerous comorbidity. Even on the basis of many similarities between these two disorders, sometimes BDD is being regarded as a spectrum of OCD (Philips, 2009).

The main characteristics of BDD which was known dysmorphic phobia in past, is preoccupation with a kind of deficiency is an individual's appearance; this deficiency is either imaginary or if there has been a body abnormality, the worries of patients about it is extreme and distressful (American Psychiatric Association, 2000).

If this worry is extreme, it cause preoccupation and impairment of social and occupational functioning and affect other dimensions of life. In such cases, there might be a personality disorder, which is pathologically interested in resolving the effect. Therefore, understanding and knowing the personality characteristics are important. In desirable situations, these patients meditate psychotherapy to perceive the real nature of neurotic feelings based on their inefficacy, otherwise persistence of this problem may cause depression in the patients.

Psychological research regarding personality disorder of cosmetic surgery volunteers showed that 70 percent of patients had a personality disorder in axis II and 19.5 percent of them had a disorder in axis I (Napoleon, 1993). On the other hand, disorders like anxiety and depression (Kolahi, 2010) and OCD (Sahebazamani et al., 2012; Philips et al., 2005) are the most prevalent disorders in clients of cosmetic surgeries which is more among females comparing to males.

Various studies have been done inside and outside the country in different areas and dimensions of BDD and personality disorders, but the comorbidity of these two disorders are not considered. Therefore, the present research is aimed to study the comorbidity of BDD and personality disorders in people who apply for cosmetic surgery.

With regard to the high prevalence of BDD throughout the world and especially in Iran, this research seems to be necessary. Using the results of this study would yield appropriate strategies to increase and improve mental health of people who apply for cosmetic surgery to society and mental health professions.

\section{METHODOLOGY}

\subsection{Statistical Population, Sample and Sampling Method}

The statistical population of present research consisted of clients (males and females) in the age range of 20 to 40 years which consulting to "Key of Beauty Clinic" without any certain problem in 2014-2015 and applied for cosmetic surgery. The sample consisted of 50 clients ( 25 males and 25 females) which estimated on the basis of df table and with regard to previous studies and selected by accessible sampling method out of the population to be investigated.

\subsection{Tests}

In this research other than the personal information questionnaire (age, gender, marital status, educational 
level), both the Milon Personality Disorder Inventory-III and BDD inventory were performed.

\subsubsection{Milon Personality Disorder Inventory-III (MCMI-III)}

This is a valid questionnaire to diagnose the personality disorders and determining its intensity. It has 175 "Yes-No" item which measures 14 clinical patterns of personality and 10 clinical symptoms and is used for adults of 18 years and above. In some regards, this questionnaire is a substitution for MMPI-2 but prominently is shorter. It is one of the most common mental test which is translated into different language and has been used in various cross-cultural studies. Its second version has been standardized in Iran (Tehran city) by Khajeh Mogahi (1993) and its third version by Sharifi (2002) in Iran, Isfahan city. After reviewing the total predictability of the questionnaire based on factor analysis of traits, results showed that diagnostic validity of all subscales is desirable; positive predictability of subscales are from 0.92 to 0.98 ; negative predictability of subscales are from 0.93 to 0.99 ; and total predictability of subscales are from 0.58 to 0.83 . The clinical patterns of personality are: schizoid (1), avoidant (2A), depressive (2B), dependent (3), histrionic (4), narcissistic (5), antisocial $(6 \mathrm{~A})$, sadistic (6B), obsessive (7), negativistic (8A), and self-defeating (8B); and intense personality disorders are schizotypal (S), borderline (C), and paranoid (P). The clinical symptoms are anxiety $(A)$, somatoform $(H)$, bipolar (manic) $(N)$, dysthymia (D), alcohol dependence (B), Posttraumatic stress disorder $(\mathrm{P})$, and drug addicted $(\mathrm{T})$; and intense clinical symptoms are thought disorder (SS), major depression (CC), and delusional disorder (PP).

\subsubsection{Body Dysmorphic Disorder Inventory}

This is a semi-structured clinical interview which has 12 items and measures cognitions, behaviors, insight levels and avoidance actions in related to body dysmorphic. Respondents show the extent of agreement with any item in a Likert scale from "I totally disagree" to "I totally agree. The alpha coefficient of the questionnaire in original culture is reported to be 0.91 . This is first translated by Rabiee et al. (2010) in Iran and its reliability and validity are being studied. Results showed that the correlation of this questionnaire with Padoa scale was 0.25 and 0.58 which shows a desirable concomitant validity. Also, the correlation between the forms in splitting method was 0.839 and coefficient of Guttmann splitting was 0.912 which shows a proper reliability.

\subsection{Procedure}

First, the necessary explanations were given to the participants who were volunteer for study and assured for confidentiality of the information. Satisfaction and cooperation, inevitability of cosmetic surgery, lack of physical cause, and necessity of surgery were some of the criteria for admission of clients who were volunteer for cosmetic surgery in the research.

\section{RESULTS}

This research is a correlational study and was investigating the relationship between BDD and personality characteristics among cosmetic surgery volunteers. To study the research hypotheses, the Pearson correlation coefficient has been used. First data obtained from questionnaires and descriptive statistics of scores have been studied.

Table 1. Means and Standard Deviations of Variables in Males and Females

\begin{tabular}{|l|c|c|c|c|}
\hline \multirow{2}{*}{ Variable } & \multicolumn{2}{c|}{ Males $(\mathbf{n = 2 5})$} & \multicolumn{2}{c|}{ Females $\mathbf{( n = 2 5 )}$} \\
\cline { 2 - 5 } & Mean & SD & Mean & SD \\
\hline BDD & 24.96 & 4.46 & 30.40 & 4.10 \\
\hline Avoidant & 56.00 & 8.79 & 62.80 & 18.82 \\
\hline Depressive & 71.96 & 9.77 & 84.12 & 14.87 \\
\hline Dependent & 37.76 & 17.01 & 41.52 & 18.76 \\
\hline Histrionic & 74.60 & 16.95 & 85.80 & 13.30 \\
\hline Narcissistic & 73.48 & 11.82 & 86.92 & 14.86 \\
\hline Antisocial & 37.96 & 14.86 & 50.84 & 12.80 \\
\hline Sadistic & 40.04 & 12.11 & 38.08 & 11.74 \\
\hline Obsessive & 84.96 & 12.68 & 90.60 & 18.96 \\
\hline Negativistic & 69.40 & 11.99 & 75.36 & 8.39 \\
\hline Self-defeating & 53.64 & 19.32 & 58.40 & 15.16 \\
\hline Schizotypal & 43.20 & 10.10 & 45.40 & 9.81 \\
\hline Borderline & 46.00 & 6.22 & 49.28 & 8.88 \\
\hline Paranoid & 50.56 & 6.00 & 47.20 & 9.13 \\
\hline
\end{tabular}




\begin{tabular}{|l|c|c|c|c|}
\hline Somatoform & 54.00 & 13.06 & 59.52 & 11.46 \\
\hline Bipolar (Manic) & 27.24 & 9.87 & 24.88 & 7.27 \\
\hline Dysthymia & 69.36 & 9.32 & 72.82 & 12.22 \\
\hline Alcohol Dependence & 39.88 & 18.47 & 39.40 & 14.70 \\
\hline Drug Addiction & 29.72 & 12.84 & 34.04 & 13.54 \\
\hline PTSD & 48.84 & 14.89 & 44.44 & 14.93 \\
\hline Thought Disorder & 49.84 & 7.18 & 53.56 & 18.99 \\
\hline Major Depression & 61.64 & 5.89 & 68.84 & 4.18 \\
\hline Delusional Disorder & 12.64 & 5.89 & 15.12 & 8.11 \\
\hline Anxiety & 74.84 & 10.74 & 82.88 & 12.22 \\
\hline
\end{tabular}

In table 1, means and standard deviations of subscales are presented for males and females. In BDD, mean scores of female are more than that of males. According to this table, in subscales of sadistic, paranoia, manic and PTSD, the mean scores of males are more than that of females.

For using Pearson correlation analyses, first the test assumptions and normality of distributions of dependent variables should be confirmed, so that the given test could be used. Therefore, to study the normality of data, Kolmogorov-Smirnoff test was used. Table 2 showed the results of Kolmogorov-Smirnoff test. According to the results of the table and obtained significant levels, all of the research variables are more than 0.05 ; so, the null hypothesis is confirmed and all subscales data are normal and to study any of the variables, the parametric tests can be used.

Table 2. Results of Kolmogorov-Smirnoff Test of one Sample

\begin{tabular}{|l|c|c|}
\hline \multicolumn{1}{|c|}{ Variables } & $\mathbf{Z}$ & Level of Sig. \\
\hline BDD & 1.00 & 0.26 \\
\hline Avoidant & 1.03 & 0.24 \\
\hline Depressive & 0.94 & 0.33 \\
\hline Dependent & 1.16 & 0.13 \\
\hline Histrionic & 0.93 & 0.35 \\
\hline Narcissistic & 1.02 & 0.24 \\
\hline Antisocial & 0.90 & 0.38 \\
\hline Sadistic & 1.22 & 0.09 \\
\hline Obsessive & 1.19 & 0.11 \\
\hline Negativistic & 1.19 & 0.11 \\
\hline Self-defeating & 0.90 & 0.38 \\
\hline Schizotypal & 0.84 & 0.47 \\
\hline Borderline & 1.00 & 0.26 \\
\hline Paranoid & 1.23 & 0.09 \\
\hline Somatoform & 1.32 & 0.06 \\
\hline Bipolar (Manic) & 1.10 & 0.17 \\
\hline Dysthymia & 1.16 & 0.13 \\
\hline Alcohol Dependence & 1.07 & 0.19 \\
\hline Drug Addiction & 1.20 & 0.11 \\
\hline PTSD & 1.24 & 0.08 \\
\hline Thought Disorder & 1.29 & 0.07 \\
\hline Major Depression & 1.04 & 0.22 \\
\hline Delusional Disorder & 1.19 & 0.11 \\
\hline Anxiety & 1.28 & 0.07 \\
\hline
\end{tabular}

In table 3, the correlation coefficients between clinical patterns of personality and BDD are presented. According to this table, the correlation between BDD with subscales of avoidant, depression, histrionic, narcissistic, obsessive and self-defeating are $0.40,0.67,0.56,0.59,0.44$ and 0.33 respectively. These relationships are significant at 0.01 and 0.05 level; but the relationships between BDD and subscales of schizoid, dependent, antisocial, sadistic and negativistic are not significant. 
Table 3. Correlation Matrix of Clinical Patterns of Personality and BDD

\begin{tabular}{|c|c|c|c|c|c|c|c|c|c|c|c|c|}
\hline 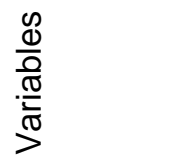 & 只 & $\begin{array}{l}\frac{N}{N} \\
\frac{N}{\mathrm{C}} \\
\stackrel{C}{N}\end{array}$ & $\frac{\mathrm{O}}{\mathrm{O}}$ & $\stackrel{0}{0}$ & $\begin{array}{l}\frac{0}{0} \\
\frac{0}{0} \\
\frac{0}{0}\end{array}$ & 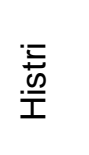 & $\begin{array}{l}\frac{0}{0} \\
\frac{0}{0.0} \\
\frac{\pi}{2}\end{array}$ & 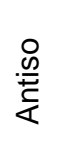 & 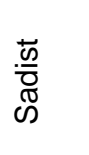 & $\begin{array}{l}0 \\
0 \\
0 \\
0 \\
00 \\
0\end{array}$ & 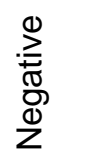 & 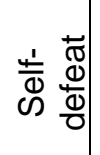 \\
\hline BDD & 1 & & & & & & & & & & & \\
\hline Schizoid & 0.25 & 1 & & & & & & & & & & \\
\hline Avoidant & $0.40^{\star \star}$ & -0.06 & 1 & & & & & & & & & \\
\hline Depressive & $0.67^{\star *}$ & 0.13 & 0.32 & 1 & & & & & & & & \\
\hline Dependent & 0.23 & 0.22 & -0.11 & 0.26 & 1 & & & & & & & \\
\hline Histrionic & $0.56^{\star *}$ & 0.02 & 0.39 & 0.40 & 0.31 & 1 & & & & & & \\
\hline Narcissist & $0.59^{\star *}$ & 0.59 & 0.22 & 0.35 & 0.40 & 0.13 & 1 & & & & & \\
\hline Antisocial & 0.26 & -0.28 & 0.36 & 0.40 & -0.10 & 0.27 & 0.31 & 1 & & & & \\
\hline sadistic & 0.27 & 0.27 & 0.31 & 0.18 & 0.20 & 0.10 & 0.32 & 0.27 & 1 & & & \\
\hline Obsessive & $0.44^{\star \star}$ & 0.13 & 0.03 & 0.37 & -0.07 & 0.14 & 0.16 & 0.20 & -0.01 & 1 & & \\
\hline Negativistic & 0.25 & -0.02 & 0.35 & 0.19 & -0.20 & 0.38 & 0.29 & 0.34 & 0.06 & 0.26 & 1 & \\
\hline Self-defeat & $0.33^{*}$ & 0.16 & 0.27 & 0.25 & 0.01 & 0.13 & 0.22 & 0.23 & 0.26 & 0.20 & 0.32 & 1 \\
\hline
\end{tabular}

In table 4, the correlation coefficients between intensive patterns of personality and BDD are presented. According to this table, the correlation between BDD and subscales of schizotypal is 0.44 which is significant at 0.01 level; but the relationship between BDD and subscales of borderline and paranoid are not significant.

Table 4. Correlational Matrix of Intense Personality Patterns and BDD

\begin{tabular}{|l|c|c|c|c|}
\hline \multicolumn{1}{|c|}{ Variables } & BDD & Schizotypal & Borderline & Paranoid \\
\hline BDD & 1 & & & \\
\hline Schizotypal & $0.44^{* *}$ & 1 & & \\
\hline Borderline & 0.26 & 0.16 & 1 & \\
\hline Paranoid & 0.14 & 0.03 & 0.16 & 1 \\
\hline
\end{tabular}

${ }^{*}$ Significant at 0.05 level $\quad{ }^{* *}$ Significant at 0.01 level

In table 5, correlation coefficients between clinical symptoms and BDD are presented. According to this table, the correlations between BDD and subscales of anxiety, somatoform, manic and dysthymia are 0.50 , $0.51,0.28$ and 0.31 respectively which are significant at 0.01 and 0.05 level; but the relationship between BDD and subscales of alcohol dependence, drug addiction and PTSD are not significant.

Table 5. Correlation Matrix of Clinical Symptoms and BDD

\begin{tabular}{|l|c|c|c|c|c|c|c|c|}
\hline Variables & BDD & Anxiety & Somato & Manic & Dysthym & Alcohol & Drug & PTSD \\
\hline BDD & 1 & & & & & & & \\
\hline Anxiety & $0.50^{* *}$ & 1 & & & & & & \\
\hline Somatoform & $0.51^{* *}$ & 0.52 & 1 & & & & & \\
\hline Manic & $0.28^{*}$ & 0.24 & 0.14 & 1 & & & & \\
\hline Dysthymia & $0.31^{*}$ & 0.29 & 0.31 & 0.09 & 1 & & & \\
\hline
\end{tabular}


IJASOS- International E-Journal of Advances in Social Sciences, Vol.II, Issue 4, April 2016

\begin{tabular}{|l|c|c|c|c|c|c|c|c|}
\hline Alcohol Dep & 0.17 & 0.07 & 0.26 & 0.30 & -0.01 & 1 & & \\
\hline Drug Addict & 0.23 & 0.09 & 0.27 & -0.18 & 0.11 & 0.12 & 1 & \\
\hline PTSD & 0.19 & 0.08 & 0.18 & 0.28 & 0.008 & 0.20 & -0.14 & 1 \\
\hline
\end{tabular}

In table 6, correlation coefficients between intense clinical symptoms and BDD are presented. According to this table, the correlation between BDD with subscales of thought disorder, major depression and delusional disorder are $0.22,0.36$ and 0.19 respectively in which the only significant relationship is between BDD and major depression and other relationships are not significant.

Table 6. Correlation Matrix of Intense Clinical Symptoms and BDD

\begin{tabular}{|l|c|c|c|c|}
\hline \multicolumn{1}{|c|}{ Variable } & BDD & Thought Disorder & Major Depression & $\begin{array}{c}\text { Delusional } \\
\text { Disorder }\end{array}$ \\
\hline BDD & 1 & & & \\
\hline Thought Dis & 0.22 & 1 & & \\
\hline Major Depression & $0.36^{* *}$ & 0.006 & 1 & \\
\hline Delusional Dis & 0.19 & -0.25 & -0.06 & 1 \\
\hline
\end{tabular}

*Significant at 0.05 level $\quad{ }^{*}$ Significant at 0.01 level

\section{DISCUSSION}

The results of the present study showed that there is a significant relationship between BDD and personality disorders and people having BDD gained high scores on scales of avoidance, depressive, histrionic, narcissistic, obsessive, schizotypal, anxiety, somatoform, manic, dysthymic and major depression.

Moreover, there was a significant difference between males and females who consulted to the "Key of Beauty Clinic". According to descriptive result of the study, the most frequency of BDD and personality disorders in female applicants.

The most important features of cluster c personality disorder is anxiety and fear. So, people with obsessive personality disorder have more consideration to rules and un-necessary details, having more feeling of control. Their feeling and situation about valuable and ethical issues, is extremely serious and inflexible (American Psychiatric Association, 2000. Results of this part of study about obsessive personality disorder in cosmetic surgery volunteers are consistent with studies by Afkham Ebrahimi \& Ghaleband (2004), Talaie et al. (2009), Rabiee et al. (2010) and Khodabandeloo (2013).

Some of the characteristics of narcissistic personality disorder is pervasive pattern of grandeur, need for praise and empathy, skills of magnification, pride and bossiness (American Psychiatric Association, 2000). The results of this part of the study is consistent with the results of study by Afkham Ebrahimi and Ghalebandi (2004) which showed that narcissistic personality pattern in volunteers of nose surgery is significantly higher than other personality patterns. Also, research by Alamdar Saravi and Ghalebandi (2004) has shown that the narcissistic personality pattern is the most prevalent personality disorder in volunteers of cosmetic surgery.

Moreover, the results of present study in subscales of clinical patterns showed that cosmetic surgery volunteers in comparison to normal population gained more scores in depressive, histrionic, narcissistic, obsessive, self-defeating, schizotypal and borderline scales. These results are consistent with previous research by Mayville et al. (1999), Conserver et al. (2003) and Breuning et al. (2010). For example, in a research which performed on 73 participants who were volunteer for cosmetic surgery, 53 percent of participants were diagnosed in axis II. Out of personality disorders, narcissistic and borderline (16.7 percent each), avoidant (12.1 percent), paranoid (9.1 percent), schizotypal and obsessive (7.6 percent each), dependent, schizoid, and histrionic (4.6 percent each) were present. Also, the intensity of reaction of people to the present defects in their appearance and decision for doing cosmetic surgery had significant relationship with intensity of their personality disorder. Similarly, results of another study showed that the prevalence of narcissistic in cosmetic surgery volunteers is high and this amount has been increased in recent years.

According to the social and psychoanalytic theories in psychology, narcissism in people has been developed 
in response to evaluations. An individual's ego might be reinforced through others' compliment. In cosmetic surgery volunteers, the mental investment on body and physical appearance is much more in comparison to normal people and it comes from extreme attention from individual's family and others to other peoples' appearance and justification about their behaviors and personal characteristics on the basis of their outward characteristics. Therefore, these people would like to be the center of attention from family, others and society in various methods and cosmetic surgery is one of the methods. Naturally, the scores of these people in narcissistic, histrionic, obsessive and self-defeating subscales are high. Also, in obsessive subscale it would be stated that this clinical pattern of personality, measures almost all cases which the opposite of it would be measured in antisocial subscale (a scale in which the plastic surgery group has gained low scores). Therefore, it is natural that this scale is higher in the items it measures. The high scores of plastic surgery applicants in clinical pattern of self-defeating and borderline can be explained by their high levels of anxiety and strong need for achievement and improvement in assumed defects in appearance and their extreme fear of others' justification and rejection by them.

On the other hand, the results of present study in subscales related to clinical symptoms of personality showed that plastic surgery group gained higher scores on somatoform (which contains BDD symptoms) and anxiety subscales. Similarly, it has been shown that more than 65 percent of patients who are admitted in therapeutic centers in order to cosmetic surgery are having BDD.

The reasons of inconsistency in some results might be different in size of studied sample and/or tools which have been used in researches and also the different environment and cultures and difference in age and genders of sample groups which affect the results.

In another study done by Philips et al. (2005), the most prevalent psychological disorders in plastic surgery volunteers were BDD, anxiety disorder, depression and also obsessive personality disorder. In this study, it is found that cosmetic surgery volunteers are having BDD, are less likely to marry, and also suicidal ideation is more, likelihood of having major depression and social phobia is higher in them and the tendency to drug abuse and addiction in them is more.

This result could be partly explained based on choice theory. As, performing such surgeries absorb a certain group of people and anyone even with defects in his/her appearance do not essay to surgery; as the results of previous research show that majority of applicant population qualify abnormalities in their mood and psychological profile. However, these abnormalities may not reach to the borderline levels, but they are symptoms of mental immaturity. One of the drawbacks and reproves of Milon questionnaire is the broad lap in its items. Some of the subscales of Milon questionnaire measure the factors which are similar to each other. So, perhaps noting the broad lap within items and subscales of the questionnaire greatly explain the elevations of depression, anxiety and thought disorder subscales. However, the amount of lap in version III which is used in this research is less than those of version I and II.

In another research which was consistent, it is reported that those categories of people who search for doing cosmetic surgery, do not gain satisfaction and search for subsequent surgeries and most probably are having BDD and personality disorder in cluster $\mathrm{B}$ and/or $\mathrm{C}$.

Researches report that mental states of people with BDD, depression and personality disorder would worsen after doing surgery and it is necessary for these people to go for psychotherapy and pharmacotherapy (if needed) before surgery interventions.

Psychological interventions especially cognitive therapy is the most effective way for such people and after a period of pharmacotherapy has the most effect on preventing relapse. In these patients the surgeries might be repeated but they won't be satisfied with the result of surgery. In fact doing more surgeries mostly worsen the situation and leads to intensify the psychological symptoms. Therefore, psychiatric evaluation to prevent the more probable impairments and treatment of psychological symptoms before plastic surgery interventions are necessary. Although serotonin reuptake inhibitors and clomipramine have shown hopeful effects on brief treatment of BDD and obsessive worries in these patients, but to permanence of such effects, using psychotherapy especially cognitive-behavior therapy has a great importance.

In general, results of present study show that majority of clients of beauty clinics represent some abnormalities in subscales of clinical symptoms and patterns and intense personality pathology. If these result also be confirmed by longitudinal studies, it means that referring the cosmetic surgery applicants to psychologists and psychiatrists has priority before doing surgery and it is expected that some of these people achieve a desirable level of mental health after psychotherapy and would not need to use higher methods of cosmetic surgery anymore which does not follow full satisfaction for people and even in many cases leads to worsen the psychological symptoms. 
However, any research in pursuing the relationships between the factors and amount of this effects, naturally has some limitations within it which make some difficulties for the research and confront with difficulties in generalization. In this research, variables such as mental health states of participants, social status, behavioral and religious beliefs could not be controlled. As in this research a self-report method has been used and bias in social desirability is involved involuntarily, there might be some distort in responses. Noting the bounded time, interviewing with participants was not possible and another limitation was the sectional study.

Therefore, to alleviate the limitation and difficulties, it is suggested that in further research, because of the limitations of the questionnaire, it is better to use other methods like structured and unstructured interview. Precise review of males and females responded separately and in larger sample sizes should be done. The variables such as social status, education, religious beliefs, effective factors in family prevalence and personality characteristics should be investigated. To study the causal relationship, performing research in a large population and using structured equations and path analysis are proposed. Also, performing longitudinal research in this population, before and after surgery and studying effective variables on surgery results are proposed.

\section{REFERENCE LIST}

Afkham Ebrahimi, A. \& Ghalebandi, M. (2004). Personality Patterns of Nose Surgery Applicants. Journal of Psychiatry and Clinical Psychology, 36, pp. 4-10.

American Psychiatric Association (2000). Diagnostic and Statistical Mental Disorder (4 ${ }^{\text {th }}$ ed.), APA.

Azizi, M.; Mahroo Zadeh, S. \& Nikravan Fard, N. (2008 a). Ethical Issues in Cosmetic Surgeries, Journal of Ethics and Medical History, 1(3), pp. 25-33.

Azizi, M.; Mahroo Zadeh, S. \& Nikravan Fard, N. (2008 b). Ethical Issues in Cosmetic Surgeries, Journal of Ethics and Medical History, 1(3), p. 28.

Breuning, E.; Oikonomou, D.; Singh, P. et al. (2010). Cosmetic Surgery in the NHS: Applying Local and National Guidelines, Journal of Plastic Reconstruct Surgery, 63, pp. 1437-1442.

Grossbart, T.A. \& Sarwer, DB. (2003). Psychosocial Issues and their Relevance to the Cosmetic Surgery Patients, Journal of Medical Surgery, 22(2), pp. 136-147.

Hamseda Analysis News Website (2010). What is the Reason of High Frequency of Cosmetic Surgery in Iran? http://www.hamseda.ir/fa/pages/?cid=3206.

Khodabandehloo, M. (2013). Body Image, Body Self-esteem. Anxiety and Depression in Clients of Beauty Clinics. Unpublished Master Thesis, Tehran University, Tehran, Iran.

Napoleon, A. (1993). The presentation of Personalities in Plastic Surgery, Annals of Plastic Surgery, 31, pp. 193-208.

Otto. M.W.; Wilhem, S.; Cohen, L.S. \& Harlow, B.L. (2001). Prevalence of BDD in a Community Sample of Women, American Journal of Psychiatry, 12, pp. 2061-2063.

Pasha, G.; Naderi, F. \& Akbari, S. (2008). Comparison of Body Image, Body Build Index, General Health and Self-concept between Beauty Surgery among those who have done Beauty Surgery and Ordinary People in Behbahan, New Findings in Psychology, 2(7), pp. 61-80.

Philips, K.A. (2009). Understanding BDD. Oxford University Press.

Rabiee, M.; Khoramdel, K.; Kalantari, M. \& Molavi, H. (2010). Factor Structure, Validity and Reliability of Modified Yale-Brown OCD Scale for BDD in Students, Journal of Psychiatric and Clinical Psychology, 15(4), pp. 343-350.

Sahebazamani, M.; Saghiri, S.; Safavi, M. \& Alavi Majd, H. (2012). Study of Relationship between Body Dysphormic Fear and OCD Symptoms in Female Students of Tehran Medical Science Schools, Journal of Rafsanjan Medical Science School, 11, 5.

Sarwer, D.B.; Cash, T.F.; Magee, L. et al. (1998). The Psychology of Cosmetic Surgery: A Review and Reconceptualization, Clinical Psychology Review, 18(1), pp. 1-22.

Sarwer, D.B.; Cash, T.F.; Magee, L. et al. (2005). Female College Students and Cosmetic Surgery: An 
Investigation of Experiences, Attitudes, and Body Image, Journal of Plastic Reconstruct Surgery, 115(3), pp. 931-938.

Swami, V. (2009). Body Appreciation, Media Influence, and Weight Status Predict Consideration of Cosmetic Surgery among Female Under-graduate, Journal of Body Image, 6, pp. 315-317.

Talaiee, A.; Fayazi Bordbar, M.; Nasiraiee, E. \& bRezaiee Ardani, E. (2009). Evaluation of Symptoms and Frequency of BDD in Students, Journal of Mashhad Medical Science University, 52(1), pp. 49-56. 